\title{
Age-Friendly Cities Performance Assessment Indicators System Validation
}

\author{
Francisco Alves Pinheiro ${ }^{1}$, Miguel Tato Diogo², Joaquim Eduardo Sousa Góis ${ }^{3}$, \\ Constança Paúl ${ }^{4}$ \\ ${ }^{1}$ Department of Production Engineering, Federal University of San Francisco Valley, Juazeiro, Brazil \\ ${ }^{2}$ Faculty of Engineering, University of Porto, Porto, Portugal \\ ${ }^{3}$ Faculty of Engineering, Porto University, Porto, Portugal \\ ${ }^{4}$ Institute of Biomedical Sciences Abel Salazar, UNIFAI/ICBAS, University of Porto, Porto, Portugal \\ Email: ${ }^{*}$ francisco alvesp@yahoo.com.br, tatodiogo@fe.up.pt, jgois@fe.up.pt, constancapaul@gmail.com
}

Received 24 March 2015; accepted 15 April 2015; published 17 April 2015

Copyright (C) 2015 by authors and Scientific Research Publishing Inc.

This work is licensed under the Creative Commons Attribution International License (CC BY).

http://creativecommons.org/licenses/by/4.0/

(c) (†) Open Access

\section{Abstract}

This study aimed to validate a set of indicators that can contribute to producing a diagnostic about the living conditions of the elderly population in the cities, serving as a powerful tool for decision making. The methodology adopted was the adaptation of the "Diagnostic content validation model”, Fehring, published in 1987. The system of indicators was based on the concept of active ageing and its determinants. Of the 38 indicators analyzed by the experts as to their appropriateness and relevance for the diagnosis and monitoring of the performance of cities to be friends of the elderly, 17 were considered critical, 19 supplementary and 2 were considered inadequate and irrelevant, being excluded from the system. Then the reliability of the questionnaire through Cronbach's alpha coefficient was calculated. The indicators proved to be useful in classifying age-friendly cities worldwide.

\section{Keywords}

Active Aging, Age-Friendly Cities, Decision Making, Indicator System, Validating Indicators

\section{Introduction}

According to data of the United Nations (UN), the world population of people aged 60 or over will double in proportion, from $11 \%$ in 2010 to $21.8 \%$ in 2050, which represents, in absolute numbers approximately two billion elderly (WHO, 2007; UN, 2009; UN, 2002).

"Corresponding author. 
The ageing population is a result of lower fertility rates in some countries below replacement rate (mean fertility of 2.1 children per woman) especially if combined with increasing life expectancy, which may be provided by some factors, such as the adoption of healthy lifestyles and active participation in their own health care at all stages of life (Muenz, 2007; WHO, 2002).

Medical advances associated with new technologies have made possible increased longevity. According to United Nations (UN, 2007a), life expectancy in 2005-1010 was 67.2 years with an estimated reach 75.4 years in 2050. In the case of developed countries it is estimated at 82.4 years and 74.3 years for the less developed regions.

Aware of the phenomenon of population ageing, the United Nations held in 2002 in Madrid, "II World Assembly on Ageing", when defining the guidelines that are to guide public policies concerning the elderly population for the XXI century. The proposals arising from this event were based on a new idea for old age, built around the concept of active ageing (Fonte, 2002: p. 1).

As a result of the Second World Assembly on Ageing, the "International Plan of Action on Ageing, 2002," was established, which among other things, provides for the empowerment of older persons to act fully and effectively in economic, political and social even through paid or voluntary work (UN, 2002).

The active ageing approach is based on the recognition of human rights of older people and the principles of independence, participation, dignity, and self-fulfillment assistance established by the United Nations (Ribeiro \& Paúl, 2011).

In this new paradigm, the strategic planning of public policies for the elderly no longer has a needs-based approach (which considers older people passive targets) and is replaced by a rights-based approach, which allows the recognition of the rights of the most old to equal opportunities and treatment in all aspects of life (WHO, 2007).

Several studies and documents of the United Nations and World Health Organization (WHO) have highlighted the importance of international research on ageing and age-related issues, as an important instrument for the formulation of policies on ageing, based on reliable indicators and uniform, prepared, among others, by organizations of national and international statistics (UN, 2002; UN, 2007b; WHO, 2007; WHO, 2011).

An active ageing approach to the development of policies and programs has the potential to meet many of the challenges inherent to individual and population ageing demanding integrated and complementary action of different public actors and civil society organizations (WHO, 2007).

This scenario points to the need for public policies that include attention to the elderly, among other concerns, diagnostic mechanisms that guide decision making by investors and public officials who deal with the subject, thus strengthening the network of care to the person elderly and promoting quality of life of this population.

\subsection{Active Ageing}

Although the old age represents a biological decline and loss of economic and social status, from the 90s, is emerging a new concept of "old" and a new way of seeing and relating to ageing (Caldas \& Thomaz, 2010). This "old modern" is guided by a model of active ageing, which has contributed to the transformation of individual and social image of the old person.

The term active ageing began to be adopted by the WHO in the late '90s to denote, "the process of optimizing opportunities for health, participation and security in order to enhance quality of life as people age” (WHO, 2007: p. 12).

This concept, different of the concepts of healthy aging and successful ageing, is based on a conception of how to achieve health, lifelong learning, and the potential welfare. Also according to the WHO, the word "active" refers to continuing participation in social, economic, cultural, spiritual and civil, and not just the ability to be physically active or to join the workforce, while the security dimension encompasses the idea of protection, dignity and care for the elderly (WHO, 2007: p. 13).

Active ageing is an emerging policy guidance from WHO, internationally, with a focus on social determinants of health, as: economic determinants, social determinants, personal determinants, behavioral determinants, physical environment, social services and health and determinants of cross-cultural and gender (Hutchison et al., 2006: p. 5; WHO, 2007: p. 19).

For Almeida (2007), the concept of active ageing is a response to concerns and goals of society, including those linked to increased costs associated with population aging. This perspective highlights the approach to 
health as a resource and not an end in itself.

Quaresma (2007) believes that the concept of active ageing has represented a strategy for governance of social security systems, especially in Europe, to delay and/or prevent early exits from the labor market. For the author, the architecture of social protection systems appropriate to a life cycle that extends and restructures, cannot but embrace a strategy of active ageing, translated the right to age with dignity and safety.

The various organizations working on this issue have actively encouraged the elderly to organize themselves to be a force able to influence the design and implementation of policies that affect them (UN, 2007b: p. 10).

\subsection{Sustainable Local Development and Active Ageing}

The dynamics of population aging is launching a challenge to current societies central to development policies. Is increasingly an issue in determining the configuration of the cities that integrates different realities and the interaction she has with its sustainability and humanization (Belo et al., 2009: p. 16).

According to Jara (1998) apparently are coming to an end the days of development driven by the centralizing state and exclusionary. The new local sustainable development strategies begin to introduce concepts of finite resources, whether natural or financial, and appreciation of space, social justice and recovery of citizenship; democratic and participatory governance, strengthening the scientific and technological capacity and market competitiveness, Local self-government and democracy, partnership and institutional responsibility.

The cities are the cultural, social and political activity centre, and in order to be sustainable, cities must provide the structures and services that enable the well-being and productivity of its inhabitants (WHO, 2009). For older people, there is need to empower engaging means to offer them support and training, compensating for physical and social changes associated with ageing.

Making cities more age-friendly is a logical and necessary response, which allows the promotion of wellness and the contribution of urban dwellers aged and still maintain prosperous cities (UN, 2002).

For the WHO (WHO, 2007: p. 1), "the age-friendly city that is capable of stimulating active ageing by creating conditions for health, participation and security in order to enhance quality of life as people age.”

The premise underlying the concept of "ageing-friendly city" is the city that a friend of the elderly is not simply friends of older people, but for everyone, especially the most vulnerable.

\subsection{Ageing-Friendly Cities}

In the Second World Assembly on Ageing, the nations represented there recognized through the "Plan of Action on Ageing, 2002", it is essential to incorporate the issue of the aging global programs:

"It is essential to recognize the ability of older persons to contribute to society by taking the lead not only in their own betterment but also in that of society as a whole. Forward thinking calls us to embrace the potential of the ageing population as a basis for future development” (UN, 2002: p. 19).

In order to help cities in planning actions to meet the demands of active ageing population and the increasing pressure of rapid urbanization, the WHO conducted a survey worldwide, distributed in 35 cities on five continents, involving governments, nongovernmental organizations and academic groups, in order to develop a mechanism for mobilization of cities to become more elderly friendly. This initiative arose "Guide Global Agefriendly Cities" (WHO, 2007).

With the publication of the guide, several initiatives have emerged around the globe, and WHO has established together with partners in several countries the "Global Network of Age-friendly Cities and Communities" (WHO, 2011), where the cities wishing to join the network must join a process diagnosis, planning, implementation and evaluation with a focus on continuous improvement of its policies and programs to become "agefriendly".

\subsection{The Process of Decision Making}

The search for information is currently the target of most governments and societies, as being important to support decision making (Feichas \& Guimarães, 2009). It is the function of the tools, which will give support to this process, to raise the necessary information in a fast, reliable, and display them in an easily understandable and indicators represent the core of these tools (Silva, 2009). 
The term "indicator" comes from the Latin Indicare, verb that means something to emphasize or reveal (Silva, 2009). In his current job indicator is understood as a tool to measure the changes in the characteristics of a system (Deponti et al., 2002).

The indicator systems as information systems used for decision support and fulfill many functions relate to the phenomena of short, medium and long term, enabling access to information already available on relevant topics as well as highlight the need for new generation information. They serve to identify variations, behaviors, processes and trends, comparisons between countries and between regions within a country, state needs and priorities for the formulation, monitoring and evaluation of policies and, ultimately, for their ability to synthesis, are able to facilitate understanding the growing audience engaged with the topic (Gomes et al., 2000; Marzall, 1999; Silva, 2009).

The process of selecting indicators should follow a set of objective criteria, achievable and verifiable to justify the choice. Generally, it is considered as valid, the following criteria: universality, reliability, measurability, consistency, availability, relevance and effectiveness (Silva, 2009).

Indicators are the visible model or set of assumptions about how the phenomenon works. They represent the subjectivity of each individual (Meadows, 1998). Therefore, the selection of indicators should help to reduce the differences between the different ways of looking at reality, without losing sight no indicator that faithfully represents the real system, are only partial reflections of this reality that tries to represent.

The use of indicators and their aggregation indices have gained increasing importance in the methodologies used to summarize the information of a technical and scientific in its original form or crude, allowing transmit it in summary form, preserving the essence of the original data and using only the variables that best serve the objectives facilitating the decision making of managers, politicians and interest groups (Marzall, 1999).

Therefore, this study aimed to validate a system of indicators to assess the performance of cities being agefriendly. This indicator system is part of a research doctorate at the University of Porto/Portugal still in progress, which aims to develop a model of performance index of age-friendly cities.

\section{Methodology}

This is an exploratory and descriptive research in order to build a system of indicators, validated by experts, to assess the performance of policies and practices to make cities more age-friendly.

The methodological plan comprehended the following three steps: identification and selection of indicators, training team of experts and analysis of indicators by experts.

\section{Steps 1: Identification and selection of indicators}

Aimed to select a set of indicators that are relevant in the assessment and monitoring of policies and practices to make cities more age-friendly.

The identification and selection of indicators occurred within the active ageing concept adopted by WHO and the discursive matrix that serves as its inspiration, e.g., the "Guide of Age-friendly Cities" and the "Global Network of Age-friendly Cities and Communities".

Identifying the indicators were sought through the literature search from secondary data in databases for statistical officers agencies, journals, thesis database, documents and initiatives developed by the agencies involved with the theme, such as the UN and WHO.

Criteria adopted for the selection of indicators were consistent with local realities, political relevance, and clarity in communication, data availability, capacity measurement over time, scientific consistency, and reliability of supply and synthesis capacity of the indicator.

Indicators research lasted for five months, held from February to June 2012, and 38 indicators related to the theme that meet the criteria were identified.

\section{Step 2: The specialist team}

The purpose of this step was to put together a multidisciplinary team able to contribute to the design and validation of the indicator system.

For Esher et al. (2012: p. 206), "a specialist is someone with the experience, skill or certain technical, scientific or practical on a specific topic". The authors concluded that within this expanded perspective, the concept of specialist ranges from academic experience to well-informed people committed to the issue studied.

The concept of expert/specialist adopted in this study refers to the individual with sound knowledge on the subject, either by training/academic specialization, either by acting experience in the subject under study. 
The inclusion criterion for the experts above mentioned, was the expert's field of R\&D expertise and the relation to the theme, besides aiming a composition that met the parity between researchers and staff with practical action and played or play activities linked to the theme of population ageing.

For the definition of the number experts to engage in the validation of the indicators, an objective or intentional non-probability sampling method was adopted. Were invited two experts, totaling twenty, for each of the following themes: Demographics, Law, Statistics, Public Administration, Urban Planning, Healthcare (medical, nursing and psychology), Occupational Safety and Road Safety and Sociology of Ageing. The average age of experts is 55 years, with a standard deviation of 12 years.

Step 3: Evaluation of the Indicators by the experts

This task had as main objective to determine the relevance of the indicators in the conceptual model of the indicators system.

To consult the experts, an adaptation of the "Method Content Validation Fehring" (Fehring, 1987) was adopted, as applied by Almeida, Seganfredo and Unicovsky (2010), in "validation of indicators to assess the nursing performance in patients with Orthopedic problems”.

The method comprehended designing a questionnaire on five-point Likert scale (Table 1), where the conceptual model was presented to the experts. Then they were asked to judge the relevance of the indicators for assessment and monitoring age-friendly cities. The assumption for the adoption of this method of validation is that the collective judgment, when well structured, it is better than the opinion of the individual.

To validate the indicators, experts gave grades in accordance to the verbal scale. Then the arithmetic mean of the scores given by the experts for each indicator was calculated. It was weighted by weights for the calculation of scores (Table 1). Indicators obtaining a mean below 0.60 , i.e. less than $60 \%$ were rejected, in order to achieve more rigorous validation. In the validation of the indicators we used the software STATISTICA (data analysis software system), version 10 (2011).

The data collection instrument was delivered in hand personally to the experts by the researcher. In only two situations, it was sent through computer (email). For all of them the research objectives were explained, how should the questionnaire be filled in and any remaining doubt cleared out. The deadline for returning the instrument was agreed with each expert according to availability.

Reliability analysis of the questionnaire

According to Trochim (2004) there are four general classes of reliability estimates, each of which estimates reliability in a different way. They are:

a) Inter-rater or inter-observer reliability, which is used to obtain the degree to which different raters provide consistent estimates of the same phenomenon;

b) Test/retest reliability, used to estimate the consistency of a measure at two different times;

c) Parallel-forms reliability, used to determine the consistency of the results of two separate surveys constructed for the same purpose, and

d) Internal consistency reliability, used to determine the consistency of the evaluation results of a survey of items.

In this study, we sought to estimate the internal consistency reliability of the questionnaire and also to estimate the inter-rater reliability, based on the analysis of the Coefficient Alpha $(\alpha)$ Cronbach. This technique was introduced in 1951 by J. Lee Cronbach as one of the estimates of the reliability of a questionnaire that has been applied in a survey (Hora, Monteiro, \& Arica, 2010).

\section{Results and Discussion}

These experts were selected for their extensive approach to the subject, either as academics or professionals with

Table 1. Likert scale, weights and criteria for selection of indicators.

\begin{tabular}{cccccc}
\hline Verbal scale & Not relevant & Little relevance & Relevant & Very relevant & Extremely relevant \\
\hline Numeric scale & 1 & 2 & 3 & 4 & 5 \\
Weighing & 0.0 & 0.25 & 0.50 & 0.75 & 1.0 \\
& & Reject & Supplementary indicator & Principal indicator \\
Criteria for indicators validation & $\leq 0.60$ & \multicolumn{2}{c}{$>0.60$ and $<0.80$} & $\geq 0.80$ \\
\hline
\end{tabular}


in-the-field performance, all with more than five years of professional experience (Table 2).

The results of the weighted arithmetic mean according to the choice of the 20 experts are presented in Table 3 according to the classification adopted for the indicators.

\section{Measure of reliability of the questionnaire}

The values of $\alpha$ vary from 0 to 1.0 , and the closer to 1 , the greater reliability of the items (questions) and reliability among evaluators.

Cronbach's $\alpha$ coefficient is calculated from the sum of the variance of individual items and the sum of the variance of each evaluator, by the Equation (1) (Cronbach, 1951: p. 299):

$$
\alpha=\left[\frac{k}{k-1}\right] \times\left[1-\left(\frac{\sum_{i=1}^{k} S i^{2}}{S \tau^{2}}\right)\right]
$$

where:

$k$ is the number of items (questions) of the questionnaire;

$\mathrm{Si}^{2}$ : corresponds to the variance of each item;

$S t^{2}$ : corresponds to the total variance of the questionnaire (sum of the variances of evaluators.

George and Mallery (2003: p. 231) provide the following classification rules:

“ $\alpha>0.9$-Excellent; $0.8<\alpha \leq 0.9$-Good; $0.7<\alpha \leq 0.8$-Acceptable; $0.6<\alpha \leq 0.7$-Questionable; $\alpha>$ 0.5 -Poor; $\alpha \leq 0.5$-Unacceptable".

According to Table 4, the reliability classification, according to the Cronbach's $\alpha$ coefficient recognizes an internal reliability of the questionnaire and evaluators as at least "Acceptable", which validates the questionnaire and its results.

Among the factors that may influence the reliability of the questionnaire, the number of items is because when more items greater reliability, which is equivalent to the concept of reducing the sampling error by increasing the sample size (Hayes, 1995). In this analysis, the internal reliability of the questionnaire calculated on all items was larger than when analyzed by dimension, which proves this assertion.

The reliability among evaluators, by dimension, has the dimension security, with 18 items was the highest values of alpha $(\alpha)$ Cronbach, and the health and participation dimensions were rated "Acceptable".

The analysis and validation of process indicators resulted in a system of indicators with 3 dimensions, 10 themes and 36 indicators (Table 5).

\section{Discussion}

Amid the indicators best evaluated, emphasis to the ones related to elderly health and safety, namely:

- Accessibility to buildings (mean 0.94), accessibility to the built environment promotes a greater participation of people with reduced mobility or disabilities to the various activities and services offered by the community;

Table 2. Experts' characterístics.

\begin{tabular}{ccc}
\hline Gender & Nr. & $\%$ \\
\hline Male & 12 & 60 \\
Female & 8 & 40 \\
Academic Degree & Nr. & $\%$ \\
Doctor & 12 & 60 \\
PhD Student & 3 & 15 \\
Master & 2 & 10 \\
Graduate & 3 & 15 \\
Field & Nr. & $\%$ \\
Academic & 10 & 50 \\
Professional & 10 & 50 \\
\hline
\end{tabular}


Table 3. Classification of indicators by experts.

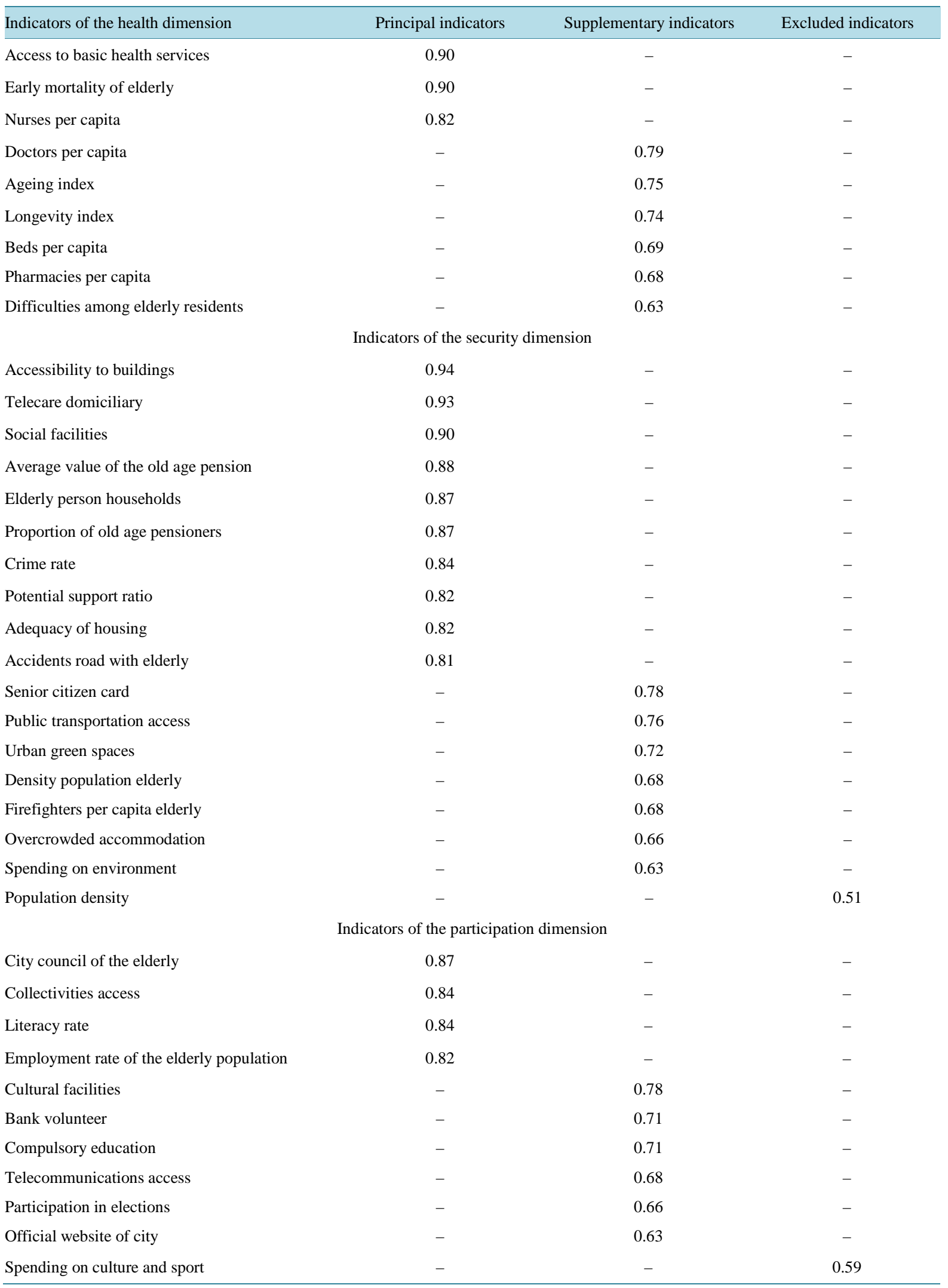


Table 4. Analysis of the internal reliability of the questionnaire and between evaluators.

\begin{tabular}{ccccccc}
\hline \multirow{2}{*}{ Questionnaire } & \multicolumn{2}{c}{$\begin{array}{c}\text { Internal reliability } \\
\text { (total evaluators) }\end{array}$} & \multicolumn{4}{c}{ Reliability among evaluators } \\
\cline { 3 - 7 } & 0.88 & Good & 0.82 & Good & 0.91 & Pcademics \\
Total of 38 items & & & Dimensions & & & Excellent \\
Health & 0.83 & Good & 0.86 & Good & 0.76 & Acceptable \\
Security & 0.82 & Good & 0.73 & Acceptable & 0.88 & Good \\
Participation & 0.62 & Acceptable & 0.61 & Acceptable & 0.62 & Acceptable \\
\hline
\end{tabular}

\section{Table 5. Conceptual model of the indicators system.}

\begin{tabular}{|c|c|c|}
\hline Dimensions & Themes & Indicators \\
\hline \multirow{17}{*}{ Security } & \multirow{5}{*}{ Housing } & 1. Adequacy of housing \\
\hline & & 2. Overcrowded accommodation \\
\hline & & 3. Accessibility to buildings \\
\hline & & 4. Elderly person households \\
\hline & & 5. Telecare domiciliary \\
\hline & \multirow{4}{*}{ Outdoor spaces } & 6. Urban green spaces \\
\hline & & 7. Crime rate \\
\hline & & 8. Density population elderly \\
\hline & & 9. Spending on environment \\
\hline & \multirow{3}{*}{ Transport } & 10. Accidents road with elderly \\
\hline & & 11. Public Transportation access \\
\hline & & 12. Firefighters per capita elderly \\
\hline & \multirow{5}{*}{ Social and financial protection } & 13. Potential support ratio \\
\hline & & 14. Proportion of old age pensioners \\
\hline & & 15. Average value of the old age pension \\
\hline & & 16. Social facilities \\
\hline & & 17. Senior citizen card \\
\hline \multirow{9}{*}{ Health } & \multirow{3}{*}{ Physical infrastructure } & 18. Access to basic health services \\
\hline & & 19. Beds per capita \\
\hline & & 20. Pharmacies per capita \\
\hline & \multirow{2}{*}{ Infrastructure human resources } & 21. Nurses per capita \\
\hline & & 22. Doctors per capita \\
\hline & \multirow{4}{*}{ Collective performance in healthcare } & 23. Ageing index \\
\hline & & 24. Longevity index \\
\hline & & 25. Early mortality of elderly \\
\hline & & 26. Difficulties among elderly residents \\
\hline \multirow{10}{*}{ Participation } & \multirow{3}{*}{ Civic participation } & 27. City council of the elderly \\
\hline & & 28. Participation in elections \\
\hline & & 29. Bank volunteer \\
\hline & \multirow{3}{*}{ Educational and laboral participation } & 30. Employment rate of the elderly \\
\hline & & 31. Literacy rate \\
\hline & & 32. Compulsory education \\
\hline & \multirow{4}{*}{ Sociocultural participation } & 33. Cultural facilities \\
\hline & & 34. Collectivities access \\
\hline & & 35. Telecommunications access \\
\hline & & 36. Official website of city \\
\hline
\end{tabular}


- Telecare domiciliary (mean 0.93), the use of technology has been considered as an asset to the care of people in a position of vulnerability, and especially when living alone or in the company of another individual in the same condition;

- To basic health care services (mean 0.90), the physical infrastructure and staff in primary health care services in all lines of work of the National Health Service, is a "sine quoi non" condition for the provision of health services to the population. Note that the mere presence of physical infrastructure is not sufficient and should be associated with an adequate number of skilled workers, especially doctors and nurses;

- Early mortality of elderly (mean 0.90 ), provides geographic variations analysis in mortality rates of the general elderly population, allowing comparative analyzes of mortality at this age. Furthermore, it supports planning, management and evaluation processes of public policies for the elderly, especially health care. It evaluates, indirectly, access and effectiveness of health services throughout life, and of prevention actions;

- Social facilities (mean 0.90), correlates vacancies offered through existing social facilities in the municipality and elderly inhabitants, allowing support for the elderly, whether in socio-familial or an institutional environment;

- Average value of the old age pension (0.88), relates the average annual value of pensions received by old age pensioners. The old age pension is intended to protect the elderly after retirement. Since pensions are supported by a national social protection system not tied to the municipality, then the higher the average value of pensions for the elderly in a given municipality, it is assumed that they are better protected financially making it a potential economic for the community and will require fewer resources and public attention at local level;

- Elderly person households (0.87), indicates the percentage of private households formed by a person aged 65 years or more compared to total private households in the municipality. It is in the family that people expect and, as a rule, get support and protection as they age. An elderly living alone requires more attention from social and institutional organizations for health and safety, especially at older ages when greater loss of functional capacity and autonomy occurs;

- Crime rate (0.84), represents the relationship between the crimes occurred and the resident population. The perception of security and the feeling of vulnerability are critical dimensions related to the subjective well-being of the individual in the relationship with the city. Thus, influencing the ability and motivation of the individual to enjoy the public space and predispose to living and active participation in community life. In the case of the elderly, this perception, correlated or not with the reality of criminal practice in the environment they live in, affects independence, physical health, social integration and emotional well-being;

- Nurses per capita (mean 0.82), the health professional (nurse) plays a key role in the care and monitoring of the health of the elderly, whether as user/customer institutionalized, either as a patient at the clinic;

- Potential support ratio (0.82), relationship between the working age population and the elderly population, usually defined as the ratio between the number of people aged between 15 and 64 years old and the number of people aged 65 years or more. Changes at the level of the age structure of the population, specifically its ageing, pose several challenges in the social and economic order of society, such as the sustainability of public social protection systems or ensure good health for the elderly, the emerging need to develop policies for active ageing.

Among the participation dimension indicators, highlight the following:

- City council of the elderly (mean 0.87 ), the city council for the protection of older people aims to contribute to improve the quality of life of older people through the political coordination, information and promotion of the rights and protection of the elderly, in order to ensure their well-being, dignity and quality of life;

- Collectivities access (mean 0.84), the community is the essence of society and plays a key role in social, cultural and sports within council's community, thru creating opportunities for active participation of the elderly in the community. These organizations provide opportunities for training and development important for the individual to take advantage of learning opportunities throughout life, an essential factor for active ageing;

- Literacy rate (mean 0.84), access to education is a fundamental condition to allow the population to have greater possibilities of insertion in the labour market and social equality;

- Employment rate of the elderly population (0.82), corresponds to the percentage of people aged from 55 who remain in the labor market. The timing of the reform is, as a rule, associated with the transition to old age, and the individual must seek ways to stay active and productive on their own, in a situation of subsistence. It is noteworthy that for society to benefit from the workforce of the older worker there needs to be an adapta- 
tion to their skills and functional capabilities, allowing the individual to decide the time of retirement itself. The following indicators were excluded:

- In the security dimension, the indicator "population density” was probably deleted by experts for its very limited usefulness as an urbanistic parameter;

- And in participation dimension, the indicator "culture and sport expenditure” was probably excluded by experts, considering that the mere expense does not allow an assessment of quality, nor its influence upon the quality of life of the elderly.

\section{Final Remarks}

According to Meadows (1998), the indicators are the visible component of models or a set of assumptions about how the phenomenon they represent works. These models and assumptions are the result of the subjectivity of each individual.

A system of indicators to assess the performance of a city pretending to be age-friendly requires a clear definition of the underlying concept and scope of the evaluation.

In this research, the indicators system comprehends the underlying concept of active ageing and its scope is to evaluate the performance of policies and programs to promote cities in becoming age-friendly. Therefore, the indicators were selected to assess the opportunities for optimization of the safety, health and participation of people as they age.

Of the 38 indicators analyzed by the experts as to their appropriateness and relevance for diagnosing and monitoring the performance of cities to be friends of the elderly, 17 were considered critical (44.73\%), 19 additional (50\%) and two were considered inadequate and irrelevant .

The proposed and validated indicators forward a system of objective indicators with measurable values and that enable a diagnosis of policies and programs towards active ageing of the population.

\section{Acknowledgements}

This work was supported by CNPq, National Council for Scientific and Technological Development—Brazil.

\section{References}

Almeida, M. A., Seganfredo, D. H., \& Unicovski, M. R. (2010). Validação de indicadores da classificação dos resultados de enfermagem para pacientes com problemas ortopédicos. Revista da Escola de Enfermagem da USP, 44, 1059-1064. http://dx.doi.org/10.1590/S0080-62342010000400029

Almeida, M. F. (2007). Envelhecimento: Activo? Bem Sucedido? Saudável? Possíveis Coordenadas de Análise... Fórum Sociológico, II Série, 17-24.

Belo, F. et al. (2009). Diagnóstico Social de Lisboa, 2009. http://habitacao.cm-lisboa.pt/documentos/1245064061D0aCC1bx8Iy10DT8.pdf

Caldas, C. P., \& Thomaz, A. F. (2010). A Velhice no Olhar do Outro: Uma perspectiva do jovem sobre o que é ser velho. RevistaKairós Gerontologia, 13, 75-89.

Cronbach, J. L. (1951). Coefficient Alpha and the Internal Structure of Tests. Psychometrika, 16, 297-334. http://dx.doi.org/10.1007/BF02310555

Deponti, C. M., Eckert, C., \& Azambuja, J. L. B. (2002). Estratégia para Construção de Indicadores para Avaliação da Sustentabilidade e Monitoramento de Sistemas. Rev. Agroecologia e Desenvolvimento Rural Sustentável, 3, 44-52.

Esher, A. et al. (2012). Construindo Critérios de Julgamento em Avaliação: Especialistas e satisfação dos usuários com a dispensação do tratamento do HIV/Aids. Ciência \& Saúde Coletiva [online], 203-214. http://dx.doi.org/10.1590/S1413-81232012000100022.

Fehring, R. (1987). Methods to Validate Nursing Diagnoses. Heart \& Lung, 16, 625-629. http://epublications.marquette.edu/cgi/viewcontent.cgi?article=1026\&context=nursing fac

Fonte, I. B. da. (2002). Diretrizes Internacionais para o Envelhecimento e suas Consequências no Conceito de Velhice. Proceedings from XII Encontro da Associação Brasileira de Estudos Populacionais [online]. OuroPreto/Minas Gerais/Brasil, 4-8 November 2002.

George, D., \& Mallery, P. (2003). SPSS for Windows Step by Step: A Simple Guide and Reference. 11.0 Update (4th ed.). Boston: Allyn \& Bacon. 
Gomes, M. L., Marcelino, M. M., \& Espada, M. da G. (2000). Proposta para um Sistema de Indicadores de Desenvolvimento Sustentável. Lisboa: Direção Geral do Ambiente-Portugal.

Guimarães, R. P., \& Feichas, S. A. Q. (2009). Desafios na construção de indicadores de sustentabilidade. Ambiente \& Sociedade, 12, 307-323. http://dx.doi.org/10.1590/S1414-753X2009000200007

Hayes, B. E. (1995). Medindo a satisfação do cliente. Rio de Janeiro: Editora Qualitymark.

Hora, H. R. M., Monteiro, G. T. R., \& Arica, J. (2010). Confiabilidade em Questionários para Qualidade: Um estudo com o Coeficiente Alfa de Cronbach. Produto \& Produção, 11, 85-103.

Hutchison, T., Morrison, P., \& Mekhaylovich, K. (2006). A Review of the Literature on Active Ageing. http://www.canberra.edu.au/centres/healthpact/attachments/pdf/active-ageing.pdf

Jara, C. J. (1998). A sustentabilidade do desenvolvimento local: Desafios de um processo em construção. Brasília: IICA: Recife/Brasil: SEPLAN, 316 p.

Marzall, K. (1999). Indicadores de Sustentabilidade para Agroecossistemas. MsC. Thesis, Porto Alegre: Federal University of Rio Grande do Sul.

Meadows, D. (1998). Indicators and Information Systems for Sustainable Development. Hartland/VT: Sustainability Institute.

Muenz, R. (2007). Aging and Demographic Change in European Societies: Main Trends and Alternative Policy Options. SP Discussion Paper No. 703. New York: Hamburg Institute for International Economics. Social Protection, World Bank.

Quaresma, M. L. (2007). Envelhecer com futuro. Fórum Sociológico, 37-42.

Ribeiro, O., \& Paúl, C. (2011). Envelhecimento Activo. In O. Ribeiro, \& C. Paúl (Eds.), Envelhecimento Activo (pp. 1-12). Lisboa: Lidel Edições Técnicas Lda.

Silva, M. G., Cândido, G. A., \& Martins, M. F. (2009). Método de construção do Índice de Desenvolvimento Local Sustentável: Uma proposta metodológica e aplicada. Revista Brasileira de Produtos Agroindustriais, Campina Grande, 11, 55-72.

Trochim, W. M. (2004). The Research Methods Knowledge Base (2nd ed.). (Version Current as of August, 2004). http://trochim.human.cornell.edu/kb/reltypes.htm

UN-United Nations (2002). Madrid International Plan of Action on Ageing. A/CONF.197/9, New York: United Nations Publication.

UN-United Nations (2007a). World Population Prospects: The 2006 Revision—Highlights. Working Paper No. ESA/P/ WP.202, New York: Department of Economic and Social Affairs, Population Division.

UN-United Nations (2007b). Research Agenda on Ageing for the 21st Century, Upgrade 2007. New York: A Joint Project of the United Nations Programme on Ageing and the International Association of Gerontology and Geriatrics.

UN_United Nations (2009). World Population Prospects: The 2008 Revision and World Urbanization Prospects: The 2009 Revision. Population Division of the Department of Economic and Social Affairs.

WHO_World Health Organization (2002). Active Ageing: A Policy Framework. WHO/NMH/NPH/02.8. http://whqlibdoc.who.int/hq/2002/WHO NMH NPH 02.8.pdf?ua=1

WHO-World Health Organization (2007). Global Age-Friendly Cities: A Guide. France: Ageing and Life Course, Family and Community Health.

WHO-World Health Organization (2011). Global Network of Age-Friendly Cities and Communities. Geneva: Ageing and Life Course, Family and Community Health. 